\title{
Artao Oronara \\ ENFRENTAMENTO DE SITUAÇÕES ADVERSAS E FAVORÁVEIS POR PESSOAS IDOSAS EM CONDIÇÕES CRÔNICAS DE SAÚDE
}

Mercedes Trentini ${ }^{1}$

Sandra H. da Silva ${ }^{2}$

Maria L. Valle ${ }^{3}$

Karina S. de A. Hammerschmidt ${ }^{4}$

Trentini M, Silva SH, Valle ML, Hammerschmidt KSA. Enfrentamento de situações adversas e favoráveis por pessoas idosas em condições crônicas de saúde. Rev Latino-am Enfermagem 2005 janeiro-fevereiro; 13(1):38-45.

Investigar as situações adversas e favoráveis vivenciadas por pessoas idosas em condições crônicas de saúde, e as estratégias de enfrentamento, foi o objetivo deste estudo. A amostra constou de 18 idosos e as informações foram obtidas por entrevistas com questões abertas. Para a análise, utilizou-se a técnica do Discurso do Sujeito Coletivo. Os resultados mostraram que a morte e a separação de familiares foram vistas como as mais significantes situações adversas. As situações favoráveis incluíram a família, sabedoria, experiência, aposentadoria e a vida em si. 0 enfrentamento se apresentou focalizado no problema e na emoção. O enfrentamento focalizado na emoção se caracterizou pelo sentimento de fé, pelo trabalho, pela busca de ajuda da família e de outras pessoas significantes, pela participação em grupo de idosos e pela rejeição às perdas naturais relacionadas ao envelhecimento. 0 enfrentamento, focalizado no problema, foi representado pela busca do atendimento médico e cuidado do corpo, numa tentativa de minimizar os problemas.

DESCRITORES: envelhecimento; doença crônica; saúde do idoso; enfermagem

\section{COPING WITH THE ADVERSE AND FAVORABLE SITUATIONS BY AGED PERSONS IN CHRONIC HEALTH CONDITIONS}

Purpose: to investigate the adverse and favorable situations experienced by elderly people in chronic health conditions, and the coping strategies. Methodology: the sample included 18 elderly. The information was collected through interviews with open questions. The "Collective Subject Discourse" technique was used for analysis. Results: the findings demonstrated that death and separation from the family were perceived as the most significant adverse situations, while the favorable situations included the family, wisdom, experience, retirement, and life itself. The coping strategies focused on the problem and the emotion. Emotion-focused coping included: belief in God, maintaining the usual activities, family and significant other support, participation in elderly social groups and rejection of losses related to the aging process. The problem-focused coping consisted of the medical treatment and body care.

DESCRIPTORS: aging; chronic disease; aged health; nursing

\section{ENFRENTAMIENTO DE SITUACIONES ADVERSAS Y FAVORABLES POR ANCIANOS EN CONDICIONES DE SALUD CRÓNICAS}

Propósito: investigar las situaciones adversas y favorables vividas por personas mayores en condiciones de salud crónicas, además de averiguar las estrategias de enfrentamiento. Método: la muestra fue compuesta por 18 ancianos. Las informaciones fueron obtenidas mediante entrevistas con cuestiones abiertas. Para el análisis se utilizó la técnica del Discurso del Sujeto Colectivo. Resultados: los hallazgos mostraron que la muerte y la separación de familiares se presentaron como las situaciones adversas las más significativas. Las situaciones favorables incluyeron la familia, sabiduría, experiencia, jubilación y la vida en si. El "coping" fue enfocado en el problema y en la emoción. El enfrentamiento focalizado en la emoción se caracterizó por el sentimiento de fe, por el trabajo, por la búsqueda de ayuda de la familia y de otras personas significativas, por el vínculo a grupos de ancianos y por el rechazo a pierdas naturales relacionadas a la vejez. El enfrentamiento focalizado en el problema fue representado por la busca de atención médica y cuidado del cuerpo, como una forma de minimizar los problemas.

DESCRIPTORES: envejecimiento; enfermedad crónica; salud del anciano; enfermería

\footnotetext{
${ }^{1}$ Enfermeira, Doutor em Enfermagem, Docente aposentada na Universidade Federal de Santa Catarina, Docente no Curso de Enfermagem, e-mail: mertini@terra.com.br;

2 Enfermeira, Doutor em Enfermagem, Diretor do Curso de Enfermagem; ${ }^{3}$ Enfermeira, Mestre em Educação, Docente no Curso de Enfermagem; ${ }^{4}$ Discente no Curso de Graduação em Enfermagem, Bolsista de Iniciação Científica do CNPq. Pontifícia Universidade Católica do Paraná
} 


\section{INTRODUÇÃO}

$\boldsymbol{A}$ vida das pessoas está mesclada por situações adversas e situações favoráveis. Amaioria delas interiorizam, com maisfacilidade, as situações adversas do que as favoráveis, e o fazem de tal maneira que as consequêencias se prolongam pelo resto da vida. As situações adversas, quando não enfrentadas adequadamente, podem levar à ansiedade e à depressão que, na maioria das vezes, atuam como "trampolim" para o desencadeamento de doenças, incluídas aquelas do tipo crônico-degenerativas, que podem se constituir em fontes de estresse.

A doença crônica pode representar uma ameaça aos projetos de vida dessas pessoas, principalmente quando se trata de pessoas idosas. As pessoas com esse tipo de doença são forçadas a manter controle rigoroso no seu estilo de vida, além da vigiância constante sobre os sinais e sintomas que, se não controlados, podem levar a situações graves e até à morte ${ }^{(1)}$. A Diabetes Mellitus é a principal causa de cegueira adquirida; metade das pessoas diabéticas apresenta hipertensão arterial e, freqüentemente, são acometidas por infecções renais ${ }^{(2)}$.

Considerando as dificuldades que as pessoas vivenciam para controlar os problemas crônicos de saúde, como também o elevado número de pessoas que procuram as instituições de saúde, repetidas vezes, para tratar dos mesmos sintomas, pode-se inferir que o modelo atual do nosso sistema de saúde está centrado no tratamento de casos agudos, e pouco responde às condições crônicas. "Para lidar com ascensão das condições crônicas, é imprescindível que os sistemas de saúde transponham esse modelo predominante. 0 tratamento agudo será sempre necessário (pois até mesmo as condições crônicas apresentam episódios agudos); contudo, os sistemas de saúde também devem adotar o conceito de tratamento de problemas de saúde de longo prazo"(3).

As pessoas em condições crônicas de saúde necessitam de apoio que vai além das intervenções tradicionais, mesmo porque a maioria das pessoas tem 60 , ou mais, anos de idade e, geralmente, encontram dificuldades em enfrentar os sintomas da cronicidade, somados às demais perdas inerentes à velhice. 0 novo modelo de saúde para as condições crônicas compreende uma estrutura que inclui uma parceria harmoniosa entre pacientes e familiares, equipes de assistência à saúde e instituições de apoio da comunidade; quando há perfeita integração dessa tríade, os pacientes participam ativamente no tratamento e prevençã̃o das condições crônicas e seus sintomas ${ }^{(3)}$.

Pressupomos que a prática educativa seja uma das estratégias adequadas a ser implementada com grupos de pessoas em condições crônicas de saúde, e deva ser direcionada de acordo com as necessidades sentidas e manifestadas pelos pacientes. Geralmente, os profissionais da saúde implementam programas de educação em saúde, de acordo com a visão de mundo deles, sem, contudo, conhecer os valores, experiências e necessidades dos usuários. Por esse motivo decidimos conduzir este estudo que, acreditamos, possa ajudar os profissionais de enfermagem a compreender melhor as situações de impacto na vida de pessoas idosas em condições crônicas de saúde e, desta forma, contribuir para o norteamento do cuidado a essa parcela da população. Portanto, este estudo responde à seguinte questão: em que consistem as situações adversas e favoráveis ocorridas no cotidiano de pessoas idosas em condições crônicas de saúde, e de que maneira são enfrentadas?

Para este estudo, adotamos a teoria do Stress and Coping ${ }^{(4)}$ que define o stress como proveniente demandas do ambiente exterior ou interior e é cognitivamente avaliado pelo indivíduo como consumindo ou excedendo seus recursos para manter seu bem-estar. 0 enfrentamento consiste em habilidades comportamentais e cognitivas utilizadas para controlar demandas internas e externas, quando avaliadas pelo sujeito como excedendo os recursos disponíveis. 0 enfrentamento tem duas principais funções: a) gerenciamento ou alteração do evento estressor; nesse caso, o enfrentamento está focalizado no problema; b) controle, redução ou eliminação das respostas emocionais ao evento estressor; esse enfrentamento está focalizado na emoção, sendo paliativo, o sujeito procura aliviar 0 estresse, ou seja, sentir-se melhor diante de um evento que não pode ser removido. Cada evento estressor é seguido de duas formas de apreciação: primária e secundária. Na primária, a pessoa examina em que ela foi atingida pela situação estressora. 0 resultado dessa apreciação contribui para a qualidade e intensidade da emoção.

Na apreciação secundária, a pessoa indaga: o que posso fazer? Quais minhas opções para enfrentar esta situação? As respostas influenciarão o tipo de estratégia que irá utilizar para lidar com tal situação. Modos de enfrentamento, focalizados no problema, serão utilizados se as conseqüências de uma situação estressante são apreciadas como sendo reversíveis, ou seja, podem ser removidas el ou alteradas; enquanto o enfrentamento focalizado na emoção é mais utilizado se as conseqüências do estressor forem apreciadas como inalteráveis. Essas duas formas de enfrentamento são interrelacionadas, visto que as pessoas, diante de um mesmo evento estressor, utilizam ambas as formas de enfrentamento, pois uma estratégia que, em princípio, está focalizada no problema, pode ter também uma função focalizada na emoção e, portanto, a emoção e 0 enfrentamento ocorrem numa relação dinâmica e recíproca ${ }^{(4)}$.

\section{OBJETIVO}

Identificar as situações adversas e favoráveis vivenciadas 
por pessoas idosas em condições crônicas de saúde e maneiras de enfrentamento utilizadas para conviver com essas situações.

\section{METODOLOGIA}

O estudo foi desenvolvido com pessoas idosas em condições crônicas, que participavam de um programa de educação para a saúde na região metropolitana de Curitiba, desenvolvido pelos professores do curso de Enfermagem da PUCPR na Paróquia Nossa Senhora da Boa Esperança. O total de idosos desse programa é de aproximadamente 250 pessoas que se subdividem em seis grupos, caracterizados como de auto-ajuda. Cada grupo reúne-se três vezes a cada semestre, para educação em saúde e auto-ajuda.

Para formar a amostra deste estudo foram convidados três idosos de cada grupo, perfazendo o total de 18. A seleção obedeceu aos seguintes critérios: ter idade igual ou acima de 60 anos, concordar em participar do estudo, e sofrer de uma ou mais doenças crônicas. A amostra se caracterizou como intencional, pois procuramos incluir pessoas de fácil comunicação. Na ocasião do convite para participar do estudo, os idosos foram informados dos objetivos do projeto e da metodologia utilizada. Os convidados foram igualmente informados de que a participação seria voluntária, sem nenhum risco para eles, e de que, se decidissem aceitar o convite, poderiam desistir a qualquer momento se assim o desejassem. Da mesma forma, foram assegurados o sigilo e anonimato referentes às informações obtidas. Foram incluídos, no estudo, aqueles que livre e espontaneamente assinaram o termo de consentimento.

As informações, gravadas em fita K7 e posteriormente transcritas, foram obtidas por entrevista com questões abertas no período de março a agosto de 2003. Os depoimentos foram analisados pela abordagem do Discurso do Sujeito Coletivo (DSC) ${ }^{(5)}$. Essa abordagem é uma proposta de organização e tabulação de dados qualitativos de natureza verbal obtidos de depoimentos.

Tal abordagem consta de quatro figuras metodológicas ${ }^{(6)}$ : a ancoragem (AC) de um discurso é a articulação desse ao referencial teórico ou à corrente filosófica em que está alicerçado. Portanto, um discurso ancorado é aquele que expressa, claramente, tendências e/ ou conceitos de uma determinada teoria e/ou ideologia. Idéia Central (IC) consiste das afirmações essenciais do conteúdo discursivo explicitadas pelos sujeitos. Expressões Chave (ECH) - são trechos das falas literais dos sujeitos que representam a síntese do conteúdo referente aos objetivos da pesquisa. Discurso do Sujeito Coletivo (DSC) - é a descrição de um discurso que representa as partes essenciais dos discursos de cada participante do estudo, elaborada de tal forma como se fosse uma pessoa falando por um grupo de pessoas.

\section{RESULTADOS}

Características dos participantes: dos 18 participantes, 17 eram do sexo feminino. Estes resultados mostram maior tendência nas mulheres em participar de ações coletivas referentes à sua saúde. Também confirmam os achados em pesquisas anteriores ${ }^{(7)}$ de que a participação masculina nos grupos de idosos é consideravelmente menor do que a feminina. Há também evidências de que, no Brasil, desde 1950, as mulheres têm maior expectativa de vida ao nascer do que os homens. Devido à oportunidade de viverem mais do que os homens, aumenta a probabilidade de as mulheres idosas viverem sozinhas e, desta forma, procurarem se relacionar com outras mulheres em situações semelhantes nos grupos de convivência.

Dois sujeitos tinham menos de 60 anos (52 e 56 anos)*. A idade dos demais variou de 60 a 80 anos. Quanto à escolaridade, 2 participantes eram analfabetos; 8 tinham $01^{\circ}$ grau incompleto; 6, 0 primeiro grau completo; 1 , o segundo grau incompleto e $1,02^{\circ}$ grau completo. Em relação à renda familiar, 10 não revelaram 0 valor; 5 ganham um salário-mínimo; 2 , dois salários, e um ganha acima de três salários.

Situações adversas

As situações adversas foram entendidas pelos participantes como as perdas e os danos sentidos por eles.

- Tema 1 - Perdas

- IC: minhas maiores perdas foram dos familiares

DSC - Eu tive várias perdas, começou com a perda do meu irmão, morreu dormindo, depois a morte de meu pai, minha mãe, meu cunhado e meus parentes. Daí engravidei e perdi meus dois primeiros filhos que eram gêmeos, foram as perdas que eu tive. Quando eu fiquei viúva, que foi minha maior perda, minha vida deu uma reviravolta, mudou $180^{\circ}$. Depois meu filho se formou e também saiu de casa, é filho único, então eu fiquei sozinha, então eu acho assim que foram perdas grandes, meu filho está aí, tudo bem, mas para casa ele não voltou mais porque hoje ele já está casado e tem até filhos.

Vale ressaltar que os participantes deste estudo, ao serem indagados sobre possíveis perdas, nenhum deles se referiu a perdas materiais e nem a perdas físicas associadas à saúde. Essas foram consideradas por eles como danos à saúde. As perdas, como mostra o discurso acima, incluem morte e separação de familiares, ou seja, perda do amor de pessoas por morte.

Todas as pessoas, qualquer que seja a idade, estão sujeitas a perdas durante o curso de vida. A perda, geralmente, é vista como algo que, inevitavelmente, acontece na velhice ${ }^{(8)}$. Para os idosos, as perdas do companheiro, de parentes e amigos, ocasionadas por morte ou separação, podem significar solidão que podem levar à depressão,

* Embora as duas pessoas não obedecessem aos critérios quanto à idade "maiores de 60 anos", foram incluídas na amostra, por vontade delas e por se sentirem idosas 
principalmente nas mulheres, visto que elas têm pouca chance de refazer a vida com outra união.

- Tema 2 - Danos

- IC: tenho vários problemas de saúde

DSC - O que mais me atrapalha na saúde é a artrose, eu não posso me ajoelhar. Tive uma crise bem forte de artrose mesmo, eu não conseguia andar. Também tenho pressão alta, diabetes, colesterol, essas coisas da velhice. Tenho problema de visão, eu não posso ficar sem óculos. O meu grande problema é que eu vivo sozinha. Quando começa a entrar o inverno, começa a depressão. Falta hormônio no meu corpo, se fico sem tomar remédio, eu passo mal, me dói tudo, uma dor de cabeça que eu deito e levanto com esta dor de cabeça. De repente, parece que desmoronou tudo no meu corpo, então acho que faz parte, como diz o médico, é tudo por causa do climatério e a menopausa que causa estas conseqüências. A gente fica mais impaciente, não tem muita paciência, fico mais ansiosa. Com o tempo veio as varizes, até agora tenho que erguer as pernas, dor nas pernas, dor no braço.

A fala "tenho pressão alta, diabetes, colesterol, essas coisas da velhice" mostra que existe a crença de que a velhice é sinônimo de doença. As crenças são imagens mentais que influenciam as emoções e, conseqüentemente, 0 corpo na sua totalidade ${ }^{(8)}$. Portanto, a doença constitui um dano à totalidade da existência, pois não são as articulações que doem, não é a pressão arterial que incomoda, mas é a totalidade existencial da pessoa que sofre ${ }^{(9)}$.

O cuidado ao idoso, além dos cuidados da artrose, da diabetes, da hipertensão, deverá incluir exercícios para mudar o modo de pensar a vida na velhice. Os idosos que sofrem calados e conformados são, da mesma forma, excluídos da sociedade e, além disso, são rotulados como: conformados, insistentes, fortes e coitados ${ }^{(8)}$.

Há quem sustente uma ideologia da velhice, que propaga a crença de que 0 envelhecimento bem-sucedido depende unicamente do indivíduo, a exemplo do médico americano Michael Roizem que declarou: "Se uma pessoa fizer tudo certo, ela pode ter uma idade biológica mais de 20 anos menor que sua idade no calendário"(10). "Tudo certo", para Roizem, significa alimentação adequada, exercícios físicos e intelectuais, exames periódicos de saúde, entre outros. Essa ideologia baseia-se no postulado de que a pessoa pode retardar ou prevenir o envelhecimento apesar das perdas biológicas e, portanto, a culpa pelo envelhecimento malsucedido é atribuída ao próprio indivíduo; todavia, questiona-se: será que a maioria da população dos países em desenvolvimento, como o Brasil, tem condições de "fazer tudo certo"? O envelhecimento bem-sucedido está associado, principalmente, às oportunidades que o indivíduo teve de usufruir a educação, urbanização, habitação, saúde, alimentação e trabalho digno durante todo o curso de sua vida ${ }^{(11)}$. É bom lembrar que, para a pessoa "fazer tudo certo", demandam, antes, políticas sociais visando os sistemas de saúde, educação, ambientes de trabalho, sistema de segurança social e modelo de formação e atuação dos profissionais.
Situações favoráveis

As situações favoráveis para esse grupo de idosos foram representadas pelos ganhos de bens referentes à família, ao crescimento pessoal, à aposentadoria e à vida.

- Tema 3 - Ganhos

- IC: meus filhos e marido foram meus maiores ganhos

DSC - Meus filhos foram meu maior ganho que já tive em toda minha vida. A gente não pára de se preocupar, aí, meus filhos foi uma benção que Deus poderia ter me dado, eles me trouxeram muita alegria nesta minha vida, muitas felicidades, muito orgulho deles. Tive um marido espetacular, ele era muito bom pra mim, muito atencioso, se dedicava à família sempre em primeiro lugar. Eu acho que eu ganhei muito na vida. Este ganho que eu tive de criar os filhos foi maravilhoso.

Parece que existe uma relação compensatória entre as perdas e os ganhos quando se trata de relações familiares. Pois, se a morte e separação de familiares foram as maiores perdas sentidas por esses idosos, os maiores ganhos também se referem aos familiares. 0 discurso acima sugere que os sentimentos referentes às perdas podem ser superados com apoio da família. Portanto, torna-se imprescindível o envolvimento dos familiares mais próximos na implementação das ações de saúde para idosos crônicos.

- IC: ganhei mais sabedoria

DSC 2 - Com o tempo também fiquei com mais sabedoria de vida; isso me trouxe um ganho muito grande, pois tenho mais força para resolver os problemas que podem aparecer neste restinho de vida que ainda me sobra para aproveitar, eu acho que é isso, a gente fica mais controlada e sábia conforme a vida passa, a gente tem que enfrentar tantos problemas, que acaba tendo certificado de como viver a vida.

- IC: mais experiência e conhecimento

DSC 3 - A gente faz amizade, depois que os filhos crescem eu apreendi muito mais as coisas da vida, artesanato, gosto bastante de fazer tricô, agora estou aprendendo teclado, não sei se vou aprender, estou tentando, toda semana eu tenho aula, estou tentando, estudando. Depois de velha começar a estudar, isso foi uma coisa espetacular eu ter conseguido completar o segundo grau, isso me deixou com mais alta estima, com mais vontade de viver por anos e anos, para ter mais e muito mais histórias pra contar. Ganhei muita experiência de vida, muita sabedoria, pra passar para os outros o que a gente aprende. Aprendi muita coisa, ser o que você tem vontade de ser, ter coragem de ser o que você é. Eu participo de teatro e muitas outras atividades que eu gosto. Há três anos atrás participei de um concurso de miss da terceira idade, foi bacana, pra mim foi uma experiência muito grande de vida. Tudo isso contribuiu porque me deu mais vontade de viver, mais força para enfrentar os obstáculos, ter mais otimismo e com certeza mais amor à minha vida.

Esses depoimentos derrubam o mito de que os idosos perdem a aptidão de aprendizagem. Na ausência de doenças degenerativas graves, os idosos têm possibilidades de conservar as competências e 
as habilidades intelectuais. Os resultados deste estudo estão congruentes com alguns achados na literatura de que as experiências, ao longo da vida, permitem a alguns idosos alcançarem elevado grau de conhecimento nas diversas áreas do saber ${ }^{(12)}$. "A velhice pode ser um tempo de colher frutos, um tempo de madureza e serenidade conquistadas, talvez a duras penas, um tempo de experiência multiplicada chamada verdadeira sabedoria"(13).

- IC: aposentadoria

DSC 4 - Pra mim, a aposentadoria me deu tranqüilidade porque quando eu trabalhava, sofri com a chuva, vento e sol. Depois que aposentei ficou bem mais tranqüilo, então a gente agradece muito a Deus. A vida da gente é feita de altos e baixos.

Se, para alguns, a aposentadoria representa uma perda, para outros, representa um ganho. Geralmente, a aposentadoria é vista como um fator negativo, principalmente quando se trata de pessoas que têm certo status social que podem sentir seu valor diminuído. No caso de trabalhadores menos favorecidos, a aposentadoria representa uma "tábua de salvação", porque estão com uma remuneração garantida sem ter que se submeter à obrigatoriedade de cumprir horários ou, ainda, para alguns, oportunidade de conseguir um ganho financeiro a mais com outro trabalho.

- IC: estar vivo

DSC 5 - Olha, o primeiro ganho vindo foi de estar vivo até hoje, foi um ganho muito gratificante porque o dinheiro não é tudo na vida da gente. Se hoje eu estou aqui, é porque Deus me permitiu isso, isso é um ganho maravilhoso, ganho não é dinheiro e sim felicidade, e alegria e eu agradeço a Deus. Eu agradeço muito a minha vida, eu tô com 75 anos e estou aqui conversando com vocês.

Esse discurso revela que os idosos podem ser felizes e alegres. Vale ressaltar a importância de estimular os idosos a manter e/ ou encontrar sentido para viver. Quem tem razão para viver supera os acontecimentos desagradáveis, aquele que não tem projeto de vida perde o sentido de sua existência e qualquer sentido para suportar 0 sofrimento ${ }^{(14)}$.

\section{Enfrentamento}

Os participantes declararam que enfrentaram as situações adversas e favoráveis com fé em Deus, ajuda da família e de outros, trabalho, freqüentando o grupo de idosos, cuidando da estética do corpo, tratamento médico e rejeição às perdas naturais conseqüentes do envelhecimento.

- IC: fé em Deus

DSC 1 - Quando acontece qualquer coisa, eu rezo muito pra Deus, eu acho que esta fé que eu tenho sempre me ajudou muito, se a gente não for forte, sempre fica pior, mas isso eu acho que faz parte da vida. Só com a força de Deus, porque sem ele você não consegue nada, hoje eu agradeço muito a
Deus. A fé nos faz viver, sem fé, você não é ninguém. A única coisa que eu peço pra Deus é saúde e ganhar o suficiente para viver a minha vidinha, rezando, brincando sempre alegre. Fé em Deus, você tem que ter fé, porque o médico pode dar um remédio para a gente, e se não tiver fé, não melhora, se você tomar um copo de água com açúcar e tiver fé, melhora. Então, a gente tem que ter muita fé e ir levando, dando força, pra enfrentar o bom e o ruim.

A fé constitui um modo de pensar construtivo. É um sentimento de confiança de que acontecerá o que se deseja. Voltando à frase do discurso: "se você tomar um copo de água com açúcar e tiver fé, melhora", essa afirmação mostra a força da fé que essas pessoas nutrem e, portanto, as ações de saúde dirigidas aos idosos precisam incluir reforços para manter e/ou desenvolver a espiritualidade, independente de qualquer credo ou convicção religiosa. O segredo do êxito constitui o fato de a pessoa estar convicta de que Deus a curará e, dessa maneira, o seu subconsciente absorve aquela idéia e faz com que a cura venha acontecer ${ }^{(15)}$. A fé sempre aumenta quando se constata que, embora invisível, a idéia, o sonho é, na verdade, real. A fé em Deus é um sentimento arraigado na nossa cultura e é tão necessária quanto são outros modos de enfrentamento; o discurso mostra que a dimensão espiritual ocupa um lugar de destaque na vida das pessoas e mostra também que é imprescindível conhecer a espiritualidade dos usuários ao planejar o cuidado de enfermagem.

- IC: enfrentei com o trabalho

DSC 2 - Quando ele morreu, eu trabalhava, então a gente saía cedo e voltava tarde, então a gente conversava com um, com outro, via muita gente, pra mim foi difícil, mas eu superei melhor. Eu trabalho e levanto cedo. Eu gosto de passear, eu passeio muito. Gosto muito de fazer exercícios, mas eu não paro, eu saio bastante, adoro viajar, mas ultimamente não está dando, o dinheiro está escasso.

Esse tipo de enfrentamento paliativo, ou seja, focalizado na emoção, pode ser interpretado na teoria da continuidade, que explica como as pessoas idosas mantêm as estruturas internas e externas preexistentes. A continuidade interna inclui memória e requer a preexistência de uma estrutura de idéias, experiências, afeto e habilidade. A continuidade externa engloba a cognição na manutenção de domínio, competência, auto-integridade e auto-estima; essa última é também motivada pelas necessidades humanas básicas ${ }^{(16)}$. Na situação relatada no discurso, a continuidade externa consiste em manter-se ativo (trabalhando, viajando e fazendo exercícios físicos), portanto, 0 cuidado ao idoso poderá incluir a motivação, para manter a continuidade de suas atividades de costume e acrescentar outras de seu agrado ao seu cotidiano, como forma de traçar seu caminho no enfrentamento das situações adversas inevitáveis.

- IC: ajuda da família e das pessoas

DSC 3 - Fui ao médico e ele falou que eu tinha que desabafar, brigar com os outros, falar sabe, mas eu pensava assim: as pessoas não têm culpa do que estou passando. Foi uma dor grande, uma perda que eu não consigo 
esquecer, eu mesmo já fui fazer tratamento, entrei em depressão, mas ainda é muito difícil de falar. Com a ajuda da minha família, conversando com as pessoas. E se você conversar com uma pessoa e ela disser, eu já passei por isso e venci, aí você pensa, se ela venceu eu também vou vencer.

O ser humano necessita de reconhecimento, de ser ouvido nas alegrias e nos infortúnios. Os medos do idoso incluem o do isolamento e, principalmente quando está sofrendo por perdas, essas impulsionam a pessoa a procurar compreensão de outras pessoas, sejam elas da família, amigas e/ou profissionais da saúde. Quanto aos profissionais da saúde, nem todos compreendem que há casos em que o tratamento não depende de medicação, mas da boa vontade em abrir um espaço para ouvir o cliente. Dados de pesquisa conduzida, num programa de saúde da família, mostram a fala de um profissional queixando-se da presença constante de uma paciente: "Tem gente que tem necessidade de usar o posto, mas tem muita gente que vem todos os dias. Tem gente que você vê de manhã, de tarde, no dia seguinte está lá de novo e assim por diante, chega uma hora que você fala: oi! Dona Maria, a senhora aqui de novo? Um dia está com dor de cabeça, no outro com dor no pé, no outro, inventa uma doença. Então este paciente tem que ser conscientizado que a Unidade de Saúde é pra quem realmente está doente, porque este paciente queima a consulta de quem precisa. Este é um problema social"(17).

Talvez essa paciente tivesse necessidade de, simplesmente, falar e ser ouvida por alguém. Não somente os idosos necessitam desse tipo de ajuda, mas todas as pessoas, em certas circunstâncias da vida, precisam de um ombro amigo, e por que não dos profissionais da saúde? Talvez esse aspecto do cuidado constitua uma lacuna na formação dos profissionais da saúde, pois quando se trata de médicos e enfermeiras, dificilmente se preocupam em detectar nos usuários necessidades "ocultas" que poderiam estar associadas aos males físicos. Os idosos são os que mais necessitam desabafar e, infelizmente, são pouco ouvidos pelas pessoas em geral e também pela maioria dos profissionais da saúde. Uma das estratégias, na promoção da saúde dos idosos e de pessoas em condições crônicas de saúde, consiste na formação de grupos de auto-ajuda que oportunizem a troca de experiências de seus pares para enfrentar situações difíceis em que, na maioria das vezes, os fatos são semelhantes.

- IC: controlo com atendimento médico e remédio

DSC 4 - Pra enfrentar tudo isso, primeiro eu procurei um médico, tentei dentro da normalidade, controlo com remédio, eu imagino que pela idade que tenho, isso acontece. Eu fui ao médico, fiz exames, e comecei fazer o tratamento, só que de vez enquanto a gente abusa, é muito difícil estar certinha e tem que enfrentar porque o que vem pra gente outro não recebe, então tem que enfrentar, não tem outra escolha.

Esse enfrentamento focalizado no problema é comum e necessário quando se trata de situações crônicas de saúde. As falas mostram também que o discurso está ancorado na crença da fatalidade: "o que vem pra gente outro não recebe", essa atitude pode levar ao conformismo e à negligência de cuidados na prevenção e na minimização dos sintomas das doenças crônicas.

- IC: freqüentando o grupo da terceira idade

DSC 5 - O grupo da terceira idade é maravilhoso, nos ajuda a enfrentar tudo de ruim que acontece, dá força pra gente viver; faz 10 anos que eu estou no grupo, estou desde o início, pra mim é maravilhoso, o grupo é a minha segunda família, quando falta uma pessoa a gente já acha falta.

Os participantes deste estudo dispõem de recursos financeiros mínimos e, desta forma, a participação no grupo de idosos parece ser a única alternativa viável para eles manterem a sociabilidade, a troca de idéias, a recreação, o aprendizado e atividades físicas. Isso mostra a importância desses grupos de convivência de idosos na promoção da saúde, pois o fato de terem um espaço onde possam ser ouvidos e ouvir os outros, faz que os idosos se sintam valorizados e úteis. Felizmente, a idéia de formar grupos de idosos está se propagando em todas as regiões do país. Essa forma de assistência pela participação, seja com idosos ou com outros segmentos da sociedade, constitui uma das estratégias para a promoção de saúde. Tratando-se dos idosos, a participação nos eventos da comunidade é uma forma para se sentirem valorizados e úteis ${ }^{(13)}$.

- IC: cuidando do corpo

DSC 6 - E com relação à aparência, na verdade, eu aceito numa boa, eu me cuido, os cabelos brancos, sempre estou pintando, sempre me cuidando.

Com esse enfrentamento focalizado no problema, as mulheres idosas mostram a vontade e a necessidade de serem usuárias de bens da tecnologia, para continuar sendo belas, atrativas para si mesmas e para os outros. É importante, para a saúde dos idosos, 0 encorajamento na busca de recursos para melhorar a imagem corporal e, conseqüentemente, sua auto-estima ${ }^{(8)}$. O estado de saúde de uma pessoa depende, também, do quanto ela se sente saudável, se mantendo a estética do corpo a pessoa se sentir bem, isso será investir na própria saúde. Por outro lado, as tecnologias antienvelhecimento têm progredido tanto que se torna impossível calcular a idade daqueles que as usufruem. Isso poderá trazer benefícios para algumas pessoas privilegiadas, mas, por outro lado, poderá afligir as pessoas excluídas desses benefícios.

- IC: não aceito as condições da idade

DSC 7 - Ah, sim! Eu falo bem francamente os danos da idade também eu não aceito, o meu mal é que todos na minha família me xingam, mas é o meu jeito de ser, tanto que agora me apareceu pressão alta, eu não aceitei, me apareceu depressão e eu também não aceitei. Eu não aceito porque ah!!!... Pois, é porque parece que desmoronou tudo em mim.

O discurso sugere que estamos frente a corpos humanos sofrendo o processo de afastamento do padrão de corpo jovem socialmente instituído, percebendo que já não são "objetos das delícias 
ilusórias do culto da juventude e se recusam a sair de cena"(16).$A$ resistência à passagem de uma fase da vida à outra pode constituir via de mão única para a depressão, solidão e ressentimentos. Rejeita-se o processo de envelhecimento e, com isso, nega-se à maturidade que vem a ser a base para um viver tranqüilo ${ }^{(17)}$. A recusa em aceitar certas condições de saúde pode levar à negação dos problemas e a rejeitar o tratamento, resultando no agravo da condição de saúde que poderá se tornar irreversível; talvez seja esse um dos motivos pelos quais muitos usuários em condições crônicas de saúde abandonam 0 tratamento, geralmente os profissionais da saúde empregam esforços para fazer com que essas pessoas adiram ao tratamento sem, no entanto, obter sucesso. Nesse caso, os profissionais deveriam procurar saber o motivo real, ou seja, o que está por trás desse abandono, pois, só então poderiam ajudar esses usuários.

\section{CONCLUSÕES}

As perdas de familiares foram consideradas as situações mais desfavoráveis na vida dos participantes, seguidas pelas condições crônicas de saúde e os sinais de envelhecimento. Os idosos utilizaram o enfrentamento focalizado na emoção e no problema.

O enfrentamento focalizado na emoção se caracterizou pelas estratégias de sentimento de fé, pelo trabalho, pela busca de ajuda da família e de outras pessoas significantes, pela participação em grupo de idosos e pela rejeição. O enfrentamento focalizado no problema foi representado pela busca do atendimento médico e cuidado do corpo, numa tentativa de minimizar os problemas.

Os achados revelaram que os participantes utilizaram múltiplas estratégias de enfrentamento para enfrentar a mesma situação estressante e que essas se apresentam inter-relacionadas e, da mesma forma que o humor humano, podem se caracterizar como incertas. Pois, ao mesmo tempo em que enfrentam pela fé, trabalho e busca de ajuda, podem enfrentar pela rejeição (Figura 1).

\section{REFERÊNCIAS BIBLIOGRÁFICAS}

1. Mazzuca SA. Does patient education in chronic disease have therapeutic value? J Chronic Dis 1982; 35:521-9.

2. Ministério da Saúde (BR). Coordenação de doenças crônicodegenerativas. Manual de Diabetes. $2^{a}$ ed. Brasília (DF): MS; 1993.

3. Organização Mundial da Saúde.Cuidados inovadores para condições crônicas: componentes estruturais de ação relatório mundial 2003. Brasília (DF): MS; 2003.

4. Lazarus RS, Folkman S. The concept of coping. In: MonartA, Lazarus RS. Stress and coping: an anthology. $3^{\mathrm{a}} \mathrm{ed}$. New York: (USA): Columbia University Press; 1991.

5. Lefévre F, Lefévre AMC, Teixeira JJV. O discurso do sujeito coletivo: uma nova abordagem metodológica em pesquisa qualitativa. Caxias do Sul RS): EDUCS; 2000.

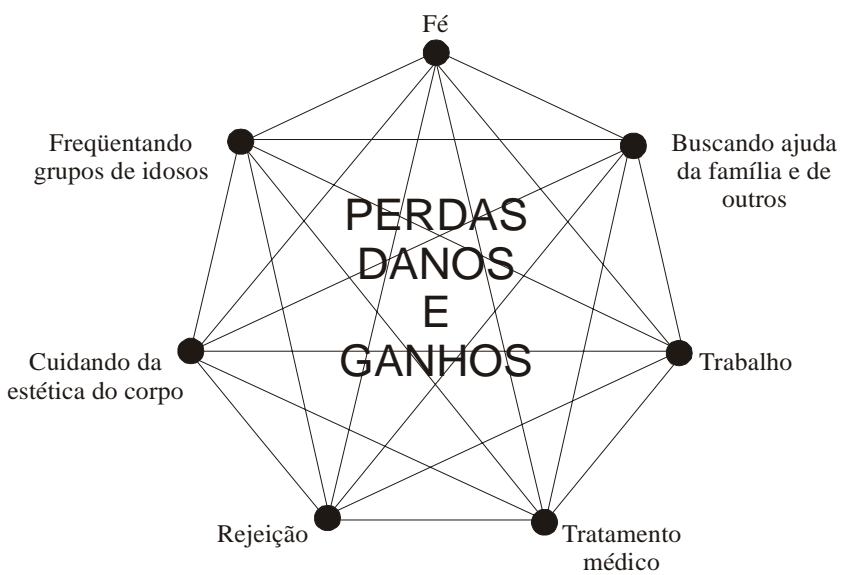

Figura 1 - Estratégias de enfrentamento e suas inter-relações

Os achados indicam que o cuidado de enfermagem dos idosos em condições crônicas de saúde não poderá se limitar ao tratamento tradicional, mas necessita abranger as experiências da vida como um todo, pois a saúde tem estreita relação com os acontecimentos cotidianos das pessoas, desta forma, vemos a necessidade de um trabalho interdisciplinar. O estudo também leva a crer que a enfermagem pode muito contribuir na qualidade de vida dessas pessoas, incentivando e organizando grupos de convivência de maneira que constitua num espaço propício para descobertas das qualidades pessoais e de troca de experiência com seus pares, manutenção e ou desenvolvimento da sociabilidade, espiritualidade e aprendizado. Dessa maneira, os idosos poderão construir uma nova perspectiva de vida, uma apreciação partilhada das situações adversas e favoráveis da vida, e encontrar maneiras saudáveis de enfrentamento. Ressaltamos a importância de estimular a participação de membros da família dos idosos nesses grupos, pois a busca de ajuda dos familiares apareceu, neste estudo, como forma de aliviar as tensões cotidianas. Nos grupos de autoajuda, os familiares dos idosos também podem se beneficiar, adquirindo maior compreensão da situação dos seus familiares idosos e, dessa maneira, podem se tornar um reforço no estímulo para a busca de múltiplas estratégias de enfrentamento.

6. Lefévre F, Lefévre AMC. O discurso do sujeito coletivo. Um novo enfoque em pesquisa qualitativa (desloreamentos). Caxias do Sul (RS): EDUCS; 2003.

7. Gonçalves LHT, Dias MM, Liz TG. Qualidade de vida de idosos independentes segundo proposta de avaliação de Flanagan. 0 mundo da Saúde. 1999 jul/ago; 23(4):214-20.

8. Monteiro PP. Envelhecer: historias; encontros; transformações. Belo Horizonte (MG): Autentica; 2001.

9. Boff L. Saber cuidar: ética do humano - compaixão pela terra. Petrópolis (RJ): Vozes; 1999.

10. Receitas da ciência para manter-se jovem aos 30, 40, 50 e 60 anos.Veja 2003 jun 11; 1806(23):53-4.

11. NeriAL. Qualidade de vida no adulto maduro: interpretações teóricas e evidencias de pesquisa. In: Neri AL. Qualidade de vida e idade madura. Campinas (SP): Papirus; 1993. 
12. Simon ORM, Giglio ZG. A arte de recriar o passado: historia oral e velhice bem sucedida. In: Neri AL, organizadora. Desenvolvimento e envelhecimento: perspectivas biológicas e sociológicas. Campinas (SP): Papirus; 2001.

13. CNBB. Vida, dignidade e esperança. Fraternidade e pessoas idosas. Campanha da Fraternidade. Texto Base CF 2003. São Paulo: Editora Salesiana; 2002.

14. FrankI VE. Em busca de sentido. Um psicólogo no campo de concentração. 17a ed. Petrópolis: Sinodal Vozes; 2003.

15. Murphy J. A força do poder cósmico do subconsciente. $21^{\mathrm{a}} \mathrm{ed}$. Rio de janeiro (RJ): Nova Era; 2002.

16. Siqueira MEC. Teorias sociológicas do envelhecimento. In: Neri AL, organizadora. Desenvolvimento e envelhecimento: perspectivas biológicas, psicológicas e sociológicas. Campinas (SP): Papirus; 2001. 17. Trentini M, Erzinger RA, Álvares LH, Albuquerque LM, Paim L, Tigrinho FC. Retrato falado do trabalho vivo em alto de uma unidade do programa de saúde da família (PSF). Texto \& Contexto Enfermagem 2003 jul/set; 12(3):351-60. 